\title{
El riesgo de disponibilidad de agua en la agricultura: una aplicación a las cuencas del Guadalquivir y del Segura
}

\author{
CARLOS DIONISIO PÉREZ BLANCO
}

Departamento de Fundamentos de Economía e Historia Económica, UNIVERSIDAD DE ALCALÁ, ESPAÑA e Instituto Madrileño de Estudios Avanzados (IMDEA-AGUA).E-mail: dionisio.perez@uah.es

\section{CARLOS MARIO GÓMEZ GÓMEZ}

Departamento de Fundamentos de Economía e Historia Económica, UNIVERSIDAD DE ALCALÁ, ESPAÑA e Instituto Madrileño de Estudios Avanzados (IMDEA-AGUA), ESPAÑA. E-mail: mario.gomez@uah.es

\section{ALBERTO DEL VILLAR GARCÍA \\ Departamento de Economía Aplicada, UNIVERSIDAD DE ALCALÁ, ESPAÑA. E-mail: alberto.delvillar@uah.es}

\section{RESUMEN}

La agricultura es un sector clave en la economía rural y constituye un motor de crecimiento en regiones del sur de España capaces de desarrollar un regadío competitivo de alto rendimiento. Este es el caso de determinadas comarcas de la Cuenca del Guadalquivir y del Segura, que no obstante afrontan los problemas derivados de la escasez creciente de agua y de un riesgo de sequía cada vez más acusado. Para responder más efectivamente a estos problemas, se han aprobado recientemente una serie de Planes de Sequía que pretenden ofrecer una respuesta planeada y anticipada que sustituya a la gestión de emergencias del pasado. En este trabajo se estudia el impacto previsible de las reglas de decisión de dichos Planes de Sequía (aprobados sin ningún estudio previo sobre las repercusiones económicas de su aplicación), con el objetivo de evaluar si estos contribuyen o no a la sostenibilidad del regadío y por lo tanto de la economía rural y regional que se sustenta sobre esta actividad económica. Se desarrolla un modelo estocástico para evaluar las pérdidas económicas derivadas de la aplicación de los Planes de Sequía en el sector agrario, concluyendo que tales planes no suponen un avance en la sostenibilidad del regadío ni en la garantía de suministro para usos prioritarios.

Palabras clave: Economía rural, economía del agua, modelos estocásticos.

\section{Water Availability Risk in Agriculture: An Application to Guadalquivir and Segura River Basins}

\begin{abstract}
Agriculture is a key sector in rural economics. In some Southern Regions of Spain capable of developing a competitive irrigation sector, agriculture is a powerful means towards development. This is the case of many comarcas of Guadalquivir and Segura River Basins, which however face a growing water scarcity and drought risk. To respond these problems in an effective manner, a series of Planes de Sequía have been approved in order to give a planned and strategic response. This paper focuses on expected impact of new decision rules established in the Planes de Sequía (which were passed without any previous economic impact analysis) and assess whether or not they contribute to irrigation sustainability and thus regional and rural economics development. This paper develops a stochastic model to assess economic loss derived from Planes de Sequía implementation over irrigated agriculture. Conclusions show that Planes de Sequía do not warrantee irrigation sustainability and priority uses water supply.
\end{abstract}

Keywords: Rural economics, water economics, stochastic models.

Clasificación JEL: Q01, Q25, Q28, Q58, Q59

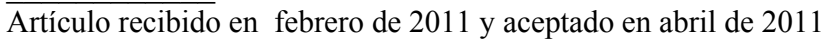

Artículo disponible en versión electrónica en la página www.revista-eea.net, ref. ə-29119 


\section{INTRODUCCIÓN ${ }^{1}$}

La agricultura es un sector clave en la economía rural y es en efecto el sector con mayores ventajas comparativas y el principal motor de crecimiento económico en regiones cuyas características geográficas y climáticas permiten el desarrollo de un regadío competitivo. Determinadas comarcas del sur de España reúnen estas condiciones (de abundancia de suelo, horas de sol, localización respecto a mercados, economías de aglomeración, etc.) pero afrontan simultáneamente un problema crónico de escasez y falta de garantía en el suministro de de agua.

La respuesta tradicional a este tipo de situaciones en España ha sido la adopción de medidas estructurales encaminadas a aumentar la provisión de los servicios del agua (Saleth et al., 1999), lo que ha mantenido a los usuarios e instituciones al margen de las fuerzas de mercado (Dinar, 2000; y Young, 2005). La demora en el desarrollo de instrumentos para aplicar políticas económicas que permitan mitigar la escasez de agua desde la óptica de la demanda (hasta los primeros años del S. XXI no se aprobaron la Ley de Aguas ${ }^{2}$, el Plan Hidrológico Nacional $^{3}$ y los Planes de Sequía de las respectivas cuencas, impulsados por la Directiva Marco del Agua ${ }^{4}$ ) ha provocado que la excesiva presión sobre los activos hídricos haya generado en determinadas zonas áridas una dinámica caracterizada por recurrentes situaciones coyunturales de sequía e incluso déficit hídricos estructurales ${ }^{5}$ (CHS y CHG, 2007; Sevilla et al., 2010).

Este es el caso de las comarcas de Campo de Cartagena y La Campiña, que en el presente trabajo tomamos como ejemplos representativos en las cuencas

\footnotetext{
${ }^{1}$ Los autores agradecen a la Unión Europea su apoyo en el desarrollo de este artículo en el marco del Proyecto Evaluating Economic Policy Instruments for Sustainable Water Management in Europe (EPI-water) (GA 265213); al Ministerio de Ciencia e Innovación en el marco del Proyecto Consolider Tragua (CSD 2006-00044); y a Agroseguro S.A., en el marco del Contrato entre la Universidad de Alcalá y la Agrupación Española de Entidades Aseguradoras de los Seguros Agrarios Combinados, S.A. para la Elaboración de un Estudio sobre la Sequía Hidrológica.

${ }^{2}$ Real Decreto Legislativo 1/2001, de 20 de julio, por el que se aprueba el texto refundido de la Ley de Aguas. BOE 24.07.2001. Es una refundición de dos textos legales básicos, además de otros complementarios: la Ley 29/1985, de 2 de agosto, de Aguas; y la Ley 46/1999, de 13 de diciembre, de modificación de la Ley 29/1985, de Aguas.

${ }^{3}$ Ley 10/2001, de 5 de julio, del Plan Hidrológico Nacional. BOE 6.07.2001.

${ }^{4}$ En España fue transpuesta al marco legislativo estatal a través de la Ley 62/2003, de 30 de diciembre de 2000.

${ }^{5}$ A pesar de la existencia de amplias infraestructuras de gran envergadura, el balance hidrológico en las zonas de referencia de este artículo (cuencas del Guadalquivir y del Segura) se caracteriza por la insuficiencia de recursos para cubrir las necesidades planteadas (déficit hidrológico). Esta situación se ve agravada en los momentos en los que aparece un episodio climático de sequía.
} 
del Segura y del Guadalquivir, respectivamente. Estas dos cuencas sufren déficit hídrico, con Índices de Explotación del Agua ${ }^{6}$ del 127\% para el Segura y del $164 \%$ para el Guadalquivir (EEA, 2009). Además, ambas demarcaciones han aprobado sus respectivos Planes de Sequía ${ }^{7}$ en el año 2007. En ellos se introducen formalmente nuevas y severas restricciones para el regadío en casos de sequía extrema, incluida la supresión total del riego en niveles de emergencia ${ }^{8}$. Tales planes hasta el momento no se han puesto en práctica debido a que desde 2008 se han sucedido años hidrológicos caracterizados por una relativa abundancia de agua.

Sin embargo, no deja de llamar la atención que hasta ahora no se haya llevado a cabo aún ningún tipo de modelización o análisis económico para evaluar las repercusiones sobre el regadío de la aplicación de estos planes. El presente artículo quiere contribuir a suplir esta deficiencia presentando, con este fin, un modelo estocástico de oferta de agua que permita evaluar el impacto de las nuevas normas de decisión sobre los rendimientos y los márgenes de los cultivos en distintos escenarios de sequía (y sus probabilidades asociadas).

Aunque existen modelos estocásticos aplicados al análisis de las precipitaciones (Martin et al., 2001) y del agua embalsada (Gómez Ramos et al., 2002), hasta el momento, estos no han sido integrados en un único modelo de evaluación del riesgo y de las consecuencias de la insuficiencia de agua para la agricultura de regadío. El modelo presentado en este artículo supone un avance en ese sentido y permite calcular el impacto de la escasez de agua (medido en porcentaje de la evapotranspiración satisfecha por precipitaciones y por regulación hídrica) sobre la producción física (medida en kilogramos por hectárea). Además, a partir de una serie de parámetros estándar de costes y precios, el modelo permite determinar el efecto de la sequía sobre los márgenes de explotación de los agricultores. Los parámetros del modelo se estiman a nivel de cuenca (precipitaciones, stock, funciones de producción) o de comarca cuando los datos microeconómicos necesarios están disponibles (coeficientes de evapotranspiración, eficiencia en el sistema de transporte, distribución y aplicación del agua de riego). Los resultados muestran que tanto la disponibilidad del recurso como su gestión por parte de las respectivas confederaciones son el principal factor determinante de la capacidad productiva de la región.

\footnotetext{
${ }^{6}$ El Water Exploitation Index (WEI) es un indicador de la presión o stress que se ejerce sobre el agua, y se calcula como el cociente entre las abstracciones totales de agua y las reservas renovables totales de agua dulce (EEA, 2009).

${ }^{7}$ Orden MAM/698/2007, de 21 de marzo.

8 Para determinar estos niveles de emergencia se utilizan indicadores pluviométricos, piezométricos y el volumen de los embalses. En las comarcas seleccionadas, el indicador de referencia es el nivel de agua embalsada.
} 
El modelo completo y su funcionamiento se ilustra con una aplicación al olivar de aceituna de aceite y al limonero ${ }^{9}$ en las comarcas de La Campiña sevillana (Cuenca del Guadalquivir) y Campo de Cartagena (Cuenca del Segura). Los resultados muestran cómo la sostenibilidad del regadío en determinadas zonas áridas de elevado rendimiento dependerá de la capacidad de la sociedad y de sus autoridades para encontrar nuevos equilibrios institucionales capaces de garantizar una provisión de agua regular y de mitigar la exposición al riesgo de sequía del agricultor.

El artículo se estructura como sigue: en primer lugar se desarrolla la metodología de evaluación del riesgo de sequía en dos subapartados: un modelo que analiza la disponibilidad de agua con una determinada probabilidad asociada y unas funciones de producción a través de las cuales se obtienen los rendimientos y el Margen Neto de Explotación (MNE) asociados a esa disponibilidad de agua. En segundo lugar se exponen los resultados, aplicados a los cultivos de limonero y olivar en las comarcas de Campo de Cartagena y La Campiña. El último apartado presenta las conclusiones y las líneas de trabajo recomendables para ulteriores trabajos de investigación.

\section{METODOLOGÍA}

La función de producción de cualquier cultivo depende de la cantidad de agua disponible, ya sea vía precipitaciones y/o regadío. La sequía se define como la insuficiencia de agua para cubrir los requerimientos de los servicios productivos y consuntivos de la población, de las actividades económicas y de los ecosistemas. Este fenómeno es función de dos variables aleatorias: i) las precipitaciones, un factor meteorológico dependiente del capital natural de la zona considerada y sujeto a la variabilidad natural vinculada al ciclo climático $^{10}$; ii) y las aportaciones al sistema de riego, dependientes de la capacidad de almacenamiento de agua en el medio natural (niveles piezométricos, aportaciones de los ríos, nivel de los neveros) y de la capacidad de regulación artificial (embalses).

\footnotetext{
${ }^{9}$ En ambas regiones el cultivo tradicional ha sido el olivar, aunque el desarrollo de técnicas para la explotación de acuíferos a gran profundidad y el desarrollo y posterior ampliación del Trasvase Tajo-Segura han provocado el declive de este cultivo en Campo de Cartagena, y su sustitución por plantaciones hortícolas y de cítricos, más intensivas en el uso del agua y con mayores márgenes. En La Campiña el olivar sigue siendo la base de la economía regional, si bien los cítricos han ganado mucha importancia y la mayor parte de las plantaciones de olivar han pasado de secano a regadío. Esta es una dinámica generalizada a nivel de cuenca, ya que el olivar en regadío en el Guadalquivir ha crecido un 105\% entre 1997 y 2008 (IAR, 2010).

${ }^{10} \mathrm{Si}$ bien este ciclo climático puede ser alterado por la acción antrópica (Naciones Unidas, 1996).
} 


\subsection{Modelo de disponibilidad de agua}

La necesidad de agua de cualquier cultivo depende de su evapotranspiración potencial $\left(\mathrm{ET}_{0}\right)$, que es la suma de la evaporación y la transpiración de la planta desde la superficie terrestre a la atmósfera. La evapotranspiración se obtiene como agregación de las evapotranspiraciones mensuales $(E T)$, siendo función de la temperatura media $\left(T_{m}\right)$, máxima $\left(T_{\max }\right)$ y mínima $\left(T_{\min }\right)$ y la radiación solar $(R a)$ y es única para cada cultivo (cada cultivo tiene su propio coeficiente mensual, $K)^{11}$ (Allen et al., 2006):

$$
\begin{gathered}
E T_{0}=0,0023 *\left(T_{m}+17,8\right) *\left(T_{\text {máx }}-T_{\text {min }}\right) * 0,5 * R a \\
E T=K * E T_{0}
\end{gathered}
$$

La evapotranspiración puede satisfacerse a través de precipitaciones y regadío. Las precipitaciones son una variable estocástica, y su impacto real sobre el cultivo se mide a través de la Precipitación Efectiva $(P E)^{12}$. La PE es función del déficit de humedad $(f(D))$, las precipitaciones $(P)$ y la evapotranspiración potencial $\left(E T_{0}\right)$. Se mide en mm anuales:

$$
E R=f(D) *\left(1,25 * P^{0,824}-2,93\right) * 10^{0,000955 * E T}{ }_{0}
$$

La evapotranspiración no cubierta mediante la PE son las Necesidades Agronómicas (NA) de la planta. Las NA deben ser cubiertas con agua de regadío, que en las comarcas de La Campiña y Campo de Cartagena proviene mayoritariamente de aguas superficiales embalsadas:

$$
N A=E T-P E
$$

El primer paso para construir el modelo consiste en analizar la frecuencia e intensidad de las precipitaciones. Para ello se calculan los parámetros correspondientes a una Función de Densidad de Probabilidad (FDP) de las precipitaciones utilizando datos históricos ${ }^{13}$. La revisión bibliográfica de

\footnotetext{
${ }^{11}$ En este estudio se parte de la evapotranspiración promedio en un año hidrológico normal, para lo cual la evapotranspiración se calcula como el promedio de la evapotranspiración en el período 1941-2009.

${ }^{12}$ La Precipitación Efectiva (PE) es función del déficit de humedad (f(D)), las precipitaciones (P) y la evapotranspiración potencial $\left(\mathrm{ET}_{0}\right)$. Se mide en mm anuales:

$$
\mathrm{ER}=\mathrm{f}(\mathrm{D}) \cdot\left[1,25 \mathrm{P}^{0,824}-2,93\right] \cdot 10^{0,000955 \cdot \mathrm{ET} 0}
$$

${ }^{13}$ Los datos de precipitaciones se obtienen del Sistema Integrado de Información del Agua (SAIH) (MARM, 2009), disponible para el período 1941-2009.
} 
referencia apunta a que la función que mejor se adapta a las precipitaciones es la función Gamma ${ }^{14}$ (McWorther et al., 1966; Martin et al., 2001):

$$
y=f(x \mid a, b)=\frac{1}{b^{a} \Gamma(a)} x^{a-1} e^{\frac{-x}{b}}
$$

Esta función permite asignar una probabilidad a cada escenario (o estado de naturaleza) de precipitaciones. La figura 1 representa la FDP para las cuencas del Guadalquivir y Segura. La aridez de ambas regiones, mayor en el Segura, hace que las mayores probabilidades se concentren en valores bajos de precipitaciones.

Figura 1

Función de Densidad de Probabilidad para las precipitaciones, cuencas del Guadalquivir y Segura, 1941-2009

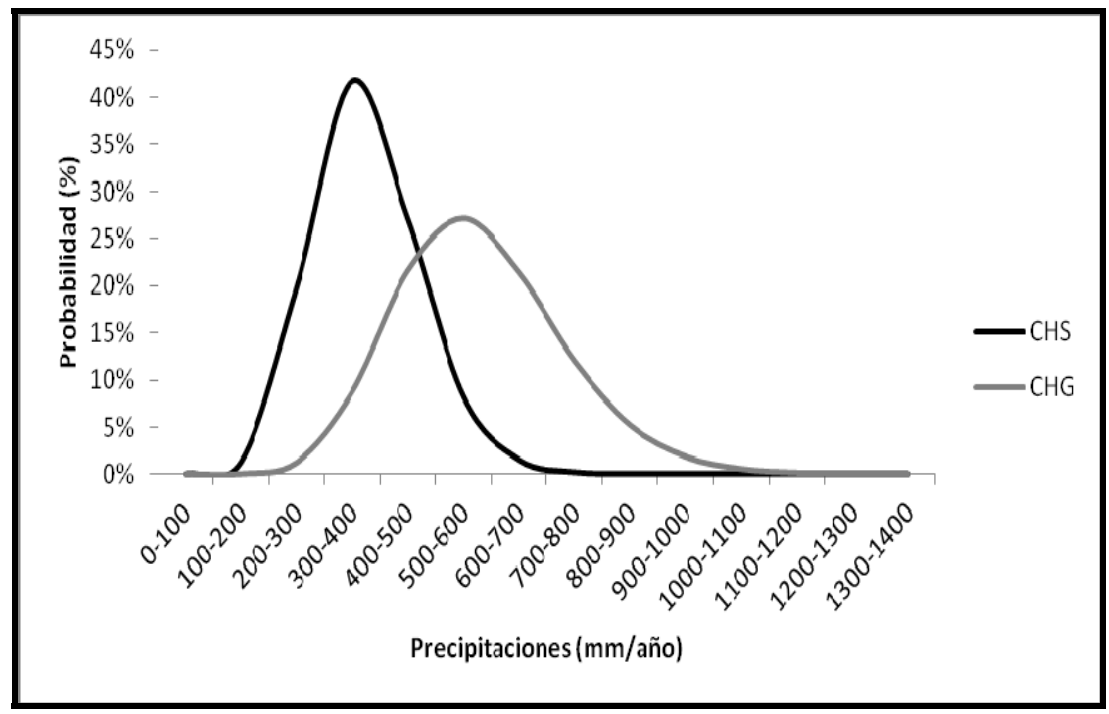

Fuente: Elaboración propia.

De esta manera se obtienen las probabilidades de ocurrencia de distintos escenarios de precipitaciones en ambas cuencas, lo que permite el cálculo de las

${ }^{14}$ La función Gamma pertenece a la familia de funciones continuas con dos parámetros, uno de escala (a) y otro de forma (b). No permite valores negativos (consistente con las precipitaciones) y alcanza un máximo en los valores intermedios. Decrece de acuerdo al valor del parámetro de escala, y se aproxima a la normal cuanto mayor es el parámetro de forma. 
Necesidades Agronómicas, y a partir de ellas de las Necesidades Agronómicas efectivas $(N A e)$, que dependen de la eficiencia en la aplicación del agua $(E r)^{15}$ :

$$
\begin{gathered}
N A_{t}=E T_{t}-P E_{t} \\
N A e_{t}=\frac{N A_{t}}{E r}
\end{gathered}
$$

El agua de regadío en las comarcas de La Campiña y Campo de Cartagena se satisface mayoritariamente a través de agua embalsada $(66,5 \%$ y $65 \%$, respectivamente), siendo también relevante el agua subterránea (33\% y $29 \%$, respectivamente) y marginal el agua residual tratada y la desalada $(0,5 \%$ y $6 \%$, respectivamente). La ausencia de series históricas suficientemente largas de indicadores de estado, aportes y salidas de acuíferos dificulta una modelización fiable de la evolución de estos recursos, por lo que se asume que, a lo largo del ejercicio de evaluación del riesgo, la cantidad provista a través de esta fuente es el resultado del producto de una constante por el porcentaje de dotaciones satisfechas, que dependen del stock de agua disponible ${ }^{16}$. El mismo supuesto se aplica al agua desalada y el agua regenerada, cuya importancia es marginal y que no dependen tanto del ciclo hidrológico como de la capacidad instalada. Como se verá más adelante las reglas de sequía imponen límites temporales sobre desembalses de agua superficial, de modo que tales supuestos permiten focalizar el análisis en las consecuencias de estas decisiones.

En ambas comarcas la cantidad de agua de disponible para el riego es función, como se verá más adelante, del nivel de stock. Por ello tiene especial relevancia el análisis probabilístico de la cantidad de agua embalsada en la cuenca. Para formalizar las reglas decisión de desembalse se desarrolla un modelo estocástico basado en el método de Montecarlo. Se parte de series históricas de stock y aportaciones a nivel de cuenca obtenidas a partir del Anuario de Aforos 2008 (Ministerio de Medio Ambiente y Medio Rural y Marino, 2008). Siguiendo a Gómez Ramos et al. (2002), se determina que el Stock de agua embalsado $\left(S_{t}\right)$ depende de las Aportaciones anuales $\left(A_{t}\right)$, los

\footnotetext{
${ }^{15}$ Las canalizaciones y las técnicas de riego determinan la cantidad final de agua que es necesario aplicar para satisfacer una determinada cantidad de NA. La eficiencia global del sistema para aguas superficiales en la comarca de Campo de Cartagena está en torno al $87 \%$, y en la de la Campiña en torno al $60 \%$.

${ }^{16}$ A esta cantidad habría que añadir las abstracciones ilegales de agua. La asunción es coherente si tenemos en cuenta la importancia de las extracciones ilegales en acuíferos y la sobreexplotación a la que son sometidos en ambas cuencas, especialmente en épocas de sequía donde las restricciones sobre las restantes fuentes de provisión de agua son mayores (CHS, 2008; CHG, 2008).
} 
aliviados de emergencia $\left(E_{t}\right)^{17}$ y el Stock almacenado en el ejercicio inmediatamente anterior $\left(S_{t-1}\right)$ (todas las variables se expresan en porcentajes sobre el total de capacidad de embalse de la cuenca):

$$
S_{t}=\alpha * S_{t-1}+\beta * A_{t}+\gamma * E_{t}
$$

Los parámetros correspondientes se ajustan mediante una regresión MCO, siendo todos ellos significativos para ambas cuencas:

Tabla 1

Valores de los parámetros de la función de estado del stock, cuencas del Guadalquivir y Segura

\begin{tabular}{|l|c|c|}
\hline Variable & Cuenca del Segura & Cuenca del Guadalquivir \\
\hline$S_{t-1}$ & $0,4^{\star *}$ & $0,62^{* *}$ \\
\hline$A_{t}$ & $0,22^{* *}$ & $1,2^{* *}$ \\
\hline$E_{t}$ & $0,15^{\star *}$ & $-0,99^{* *}$ \\
\hline$R^{2}$ & 92,68 & 95,01 \\
\hline
\end{tabular}

** Significativo al 5\%

Fuente: Elaboración propia.

Una vez ajustados los parámetros se calcula una FDP para los aportes anuales, usando de nuevo una función Gamma. A partir de la FDP obtenida se generan 200 valores aleatorios de $A_{t}$, con lo que se evitan los problemas que se pudieran derivar de la escasez de datos para algunos embalses y determinados años. Introduciendo estos valores aleatorios en la ecuación anterior, se generan 200 valores para $S_{t}$, y a partir de estos datos se puede ajustar una FDP para el stock. La función que mejor se ajusta en este caso es una función Weibull (Gómez-Ramos et al., 2001) ${ }^{18}$ :

$$
y=f(x \mid a, b)=\frac{b}{a}\left(\frac{a}{b}\right)^{b-1} e^{-\left(\frac{x}{a}\right)^{b}}
$$

La FDP Weibull presenta la probabilidad de alcanzar un determinado nivel de stock medido como porcentaje sobre la capacidad total de la Cuenca. Las

\footnotetext{
${ }^{17}$ Esta variable adopta valores positives si la suma de $S_{t-1}$ y $A_{t}$ es mayor que el 90\% (volumen máximo de seguridad). Si es negativa, $E_{t}=0$.

18 La función Weibull es una función de distribución de probabilidad continua con dos parámetros: uno de escala (a) y otro de forma (b).
} 
probabilidades más altas para el Guadalquivir se encuentran de nuevo a niveles de mayor disponibilidad de agua (50-70\%) que en la Cuenca del Segura (20$40 \%$ ), consecuencia de la mayor aridez de esta última.

Figura 2

Función Weibull de densidad de probabilidad del stock embalsado, cuencas del Guadalquivir (CHG) y Segura (CHS)

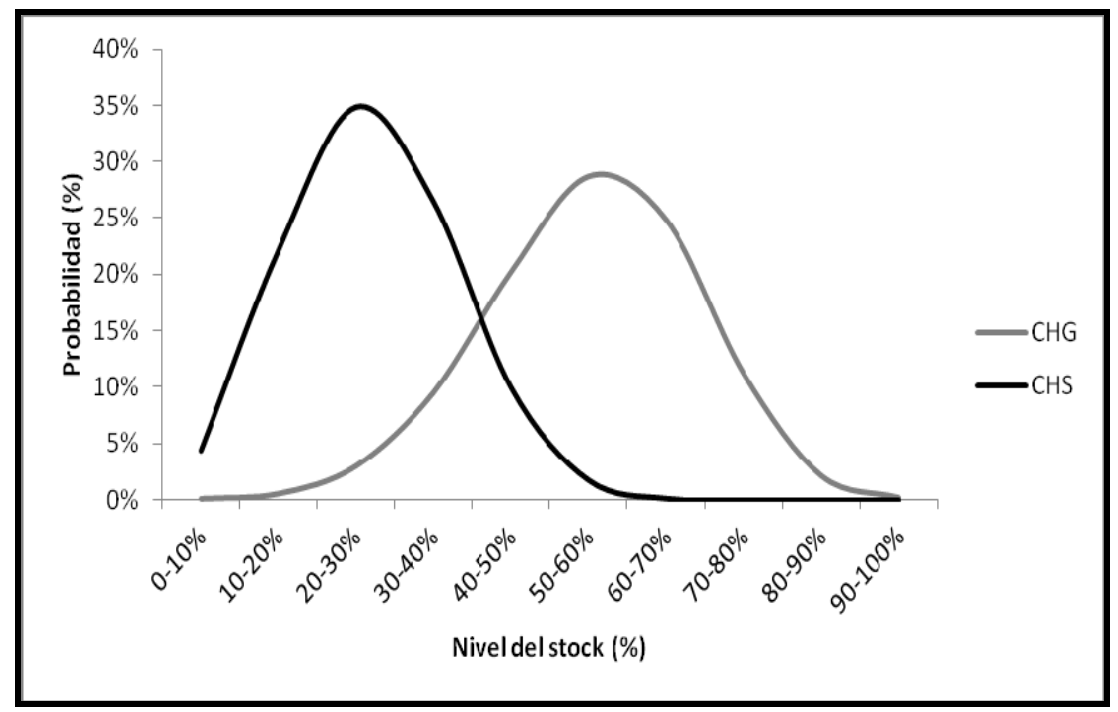

Fuente: Elaboración propia.

Una vez calculada la probabilidad con la que se dispone de una determinada cantidad de agua embalsada, es preciso calcular las Necesidades Agronómicas Efectivas que se pueden satisfacer con ese nivel de stock. La decisión de cuánta agua conceder para el regadío es un proceso institucional en el que participan los distintos organismos integrantes de la Confederación correspondiente ${ }^{19}$. Los nuevos Planes de Sequía establecen indicadores de referencia para cada Junta de Explotación y distintos niveles a partir de los cuales no se puede suministrar

${ }^{19}$ La Confederación establece para cada año una cantidad de Necesidades Agronómicas Efectivas (NAe) teóricas a satisfacer para cubrir la evapotranspiración. Estas NAe se calculan para cada cultivo siguiendo un criterio maximalista. La cantidad de NAe se estima como las NA necesarias para cubrir el $80^{\circ}$ percentil de la evapotranspiración histórica anual (período 19412009) asumiendo una eficiencia global del sistema del 60\% (MARM, 2008). Como la evapotranspiración se fija como un promedio de la evapotranspiración histórica y la eficiencia del sistema es mayor o igual que la asumida en este cálculo maximalista, las NAe pueden ser cubiertas habitualmente son una menor cantidad de agua de la prevista (salvo en situaciones de sequía). 
agua para el riego (niveles de emergencia ${ }^{20}$ ) (CHS y CHG, 2007). En el caso de las dos comarcas seleccionadas los indicadores de referencia se refieren al nivel de llenado de los embalses, por lo que se asume que por debajo de un determinado nivel de agua embalsada no se suministra agua para riego (si bien las abstracciones ilegales de agua subterránea pueden continuar). Fuera de estos niveles, la decisión es discrecional y se pueden anticipar las Dotaciones de agua de Regadío $\left(D R_{t}\right)$ observando las decisiones tomadas en el pasado. La variable explicativa fundamental en este caso es el stock de agua embalsada, siendo la función cuadrática la que mejor ajuste ofrece:

$$
D R_{t}=\lambda * S_{t}+\theta * S_{t}^{2}
$$

La siguiente tabla recoge el valor de los coeficientes de la ecuación anterior para cada una de las cuencas consideradas:

Tabla 2

Coeficientes del modelo estocástico de embalses, cuencas del Guadalquivir y del Segura

\begin{tabular}{|l|c|c|}
\hline Variable & Cuenca del Segura & Cuenca del Guadalquivir \\
\hline$S_{t}$ & $0,99^{* *}$ & $0,62^{* *}$ \\
\hline$S_{t}{ }^{2}$ & $-1,94^{* *}$ & - \\
\hline$R^{2}$ & 92,68 & 95,01 \\
\hline
\end{tabular}

** Significativo al 5\%

Fuente: Elaboración propia.

Condicionando las probabilidades de satisfacer una determinada dotación de riego a las obtenidas para las precipitaciones, se obtiene una matriz que permite asignar a cada escenario de precipitaciones y nivel de stock una determinada probabilidad. Las tablas correspondientes a las comarcas de La Campiña y Campo de Cartagena se pueden consultar en el Anexo I.

El modelo hasta ahora calcula el porcentaje de evapotranspiración $\left(E T c_{t}\right)$ que es satisfecho vía precipitaciones $\left(P E_{t}\right)$, agua embalsada $\left(D R_{t}\right)$, agua subterránea $\left(S U B_{t}\right)$, agua residual tratada $\left(A R_{t}\right)$ y agua desalada $\left(D S_{t}\right)$ sobre la evapotranspiración total del cultivo $\left(E T_{t}\right)$ en cada escenario y con una determinada probabilidad. La diferencia entre el $D R_{t}$ y la $N A e_{t}$ son las

${ }^{20}$ En la CHS, el umbral de emergencia en todos los sistemas está en el $20 \%$ del stock (CHS, 2007); en el Sistema de Regulación General dentro de la CHG, del que depende La Campiña, el umbral de emergencia está en el 30\% (CHG, 2007). 
necesidades de agua de regadío que no pueden ser cubiertas $\left(D H_{t}\right.$, déficit hídrico del cultivo).

$$
\begin{gathered}
P E_{t}=f\left(P_{t}\right) \\
D R_{t}=f\left(S_{t}\right) \\
E T c_{t}=\frac{P E_{t}+\frac{D R_{t}}{E r}+A R_{t}+D S_{t}+S U B_{t}}{E T_{t}} \\
D H_{t}=1-E T c_{t}
\end{gathered}
$$

Este proceso debe replicarse para cada cultivo y comarca considerado ${ }^{21}$.

\subsection{Impacto económico de la sequía y cuantificación del riesgo}

Una vez determinada el agua disponible en cada estado del sistema y la probabilidad asociada, el siguiente paso consiste en obtener la producción y el Margen Neto de Explotación (MNE) asociados.

Simplificar la producción de un cultivo haciéndola depender exclusivamente del nivel de satisfacción de las necesidades hídricas o del suministro de agua, presenta el inconveniente de obviar otros factores que inciden en su productividad (clases de suelos, consideraciones acerca de la aplicación de fertilizantes y fitosanitarios, diferentes variables climáticas, etc.). No obstante, considerando el resto de los factores que inciden en el rendimiento de los cultivos como constantes, es posible obtener resultados con una cierta garantía de rigor y aproximación a la realidad; al menos en lo que se refiere a la forma y estructura de la función de producción de los cultivos:

$$
Q_{t}=f\left(E T c_{t}\right)
$$

Para identificar la función de producción de este tipo de cultivos se ha recurrido a distintas fuentes académicas y organizaciones del sector agrario. Entre estas últimas se encuentra el Sindicato Central de Regantes del Acueducto Tajo-Segura (SCRATS), que a mediados de 2005 elaboró un informe sobre las repercusiones de la sequía de los años 2004-2005 ${ }^{22}$, incluyendo algunas funciones de producción de diferentes cultivos, fundamentalmente cítricos. Las funciones de producción utilizadas en ese informe sirven en nuestro estudio de caso de referencia para el cálculo de los rendimientos del limonero.

\footnotetext{
${ }^{21}$ La mayor parte de los parámetros del modelo se pueden emplear a escala de cuenca, si bien hay parámetros particulares para cada comarca (eficiencia global del sistema de riego) y para cada comarca y planta (coeficientes $K$ ).

${ }^{22}$ SCRATS (2005), Informe sobre las repercusiones de la sequía 2004-2005. Junio 2005. Murcia.
} 
En el caso del olivar, se ha recurrido a diversos trabajos desarrollados por la Universidad de Córdoba y la Junta de Andalucía, que obtienen la función de producción bajo diversas situaciones de riego en aplicación de técnicas de Riego Deficitario Controlado (RDC) (Pastor et al., 2002).

Una vez identificada la función de producción de referencia, se traslada a las situaciones concretas dentro de cada región. Al no disponerse de información suficientemente desagregada a nivel de comarca, el cálculo se realiza dentro de la circunscripción provincial, que es el mayor nivel de desagregación con información disponible (MARM, 2009). El supuesto implícito utilizado para implementar las funciones de producción en cada localización consiste en asumir que las características locales pueden ser consideradas como efectos fijos que, en consecuencia, desplazan la función de producción, pero mantienen su forma funcional, sus productividades marginales y su elasticidad. Los datos observados permiten establecer la magnitud de estos efectos fijos en el extremo superior para un año en que, de acuerdo con las series de datos disponibles, se hayan satisfecho en su totalidad las necesidades agronómicas de agua y, por lo tanto, se hayan obtenido los rendimientos máximos ${ }^{23}$. Este valor máximo se ha obtenido a partir del valor de producción localizado en un ejercicio calificado como húmedo en la provincia de estudio ${ }^{24}$.

Las funciones de producción resultantes son cuadráticas, adoptando la siguiente forma:

$$
Q_{t}=\lambda+\beta * E T s_{t}+\alpha * E T s_{t}^{2}
$$

\section{Tabla 3}

Funciones de producción del olivar y el limonero $\left(Q_{t}\right)$ en Campo de Cartagena (Cuenca del Segura) y La Campiña (Cuenca del Guadalquivir)

\begin{tabular}{|l|c|c|}
\hline $\begin{array}{c}\text { Cultivo I } \\
\text { Comarca }\end{array}$ & La Campiña (Sevilla) & Campo de Cartagena (Murcia) \\
\hline Olivar & $Q_{t}=-3518,5^{*}\left(E T c_{t}\right)^{2}+10745^{*}\left(E T c_{t}\right)-3016,5$ & $Q_{t}=-3597,9^{*}\left(E T c_{t}\right)^{2}+10987^{*}\left(E T c_{t}\right)-3084,5$ \\
\hline Limonero & $Q_{t}=-21105^{*}\left(E T c_{t}\right)^{2}+66256^{*}\left(E T c_{t}\right)-16,528$ & $Q_{t}=-16967^{*}\left(E T c_{t}\right)^{2}+53265^{*}\left(E T c_{t}\right)-313288$ \\
\hline
\end{tabular}

Fuente: Elaboración propia a partir de SCRATS (2005), Pastor et al. (2002) y MARM (2009).

\footnotetext{
${ }^{23} \mathrm{Si}$ bien esto no es cierto para todos los cultivos (hay casos en los que el riego deficitario arroja mayores rendimientos), sí lo es en el caso de los cítricos (SCRATS, 2005).

${ }^{24}$ Calificado por el Instituto Nacional de Meteorología (INM), o la Agencia Estatal de Meteorología (AEMET) que lo sustituye a partir de 2008.
} 
El siguiente paso es el análisis financiero de la producción, que calcula el Margen Neto de Explotación (MNE) por cultivo y comarca medido en $€ /$ ha. Se obtiene en primer lugar el valor de la producción ( $V t)$ partiendo de los datos de producción y los precios observados en el mercado $\left(P_{t}\right)^{25}$. A esta cantidad hay que sumarle las subvenciones ${ }^{26}$ pata obtener los ingresos totales. Los costes en los que se incurre en el proceso productivo se agrupan siguiendo la clasificación de los Informes Técnicos de Sistemas de Explotación Agraria (MARM, 2007) en costes directos excluidos la mano de obra fija y la maquinaria $\left(C D_{t}\right)$, costes de maquinaria $\left(C M_{t}\right)$, costes de mano de obra fija $\left(M O f_{t}\right)$, costes de mano de obra variables $\left(M O v_{t}\right)$ y costes de aplicación de agua $\left(C A_{t}\right)$. La diferencia entre los ingresos y los costes es el Margen Neto de la Explotación $\left(M N E_{t}\right)$ en euros por hectárea:

$$
\begin{gathered}
Q_{t}=f\left(E T s_{t}\right) \\
V_{t}=Q_{t} * P_{t} \\
M N E_{t}=V_{t}+S_{t}-\left(C D_{t}+C M_{t}+M O f_{t}+M O v_{t}+C A_{t}\right)
\end{gathered}
$$

Los costes directos (excluidos mano de obra fija y maquinaria) y de maquinaria dependen linealmente de la producción y se calculan multiplicando esta por un parámetro obtenido a partir del Informe Técnico Económico de Sistemas de Explotación Agrarias (MARM, 2007). Estos costes varían por provincia y cultivo:

$$
\begin{aligned}
& C D_{t}=Q_{t} * \delta \\
& C M_{t}=Q_{t} * \varepsilon
\end{aligned}
$$

Los costes de MOf se obtienen multiplicando el coste de un jornal ( $\zeta$ ) por el número de jornales promedio de MOf empleados en ese cultivo $\left(J_{t}^{v}\right)$ (parámetro fijo), mientras que en el caso de la MOv se multiplica el número de

\footnotetext{
${ }^{25}$ El análisis sobre la producción y márgenes de explotación se desarrolla a escala comarcal, por lo que shocks negativos/positivos en la comarca analizada pueden verse compensados por otros positivos/negativos en comarcas próximas. Los precios reales (descontada la inflación) de referencia en la metodología para los productos analizados se corresponden con los del mercado mayorista a un nivel superior al de la comarca (MARM, 2009). En este modelo asumimos que la cantidad producida anualmente crece a la misma tasa que la demanda, con lo que los precios reales son constantes.

Este supuesto es aceptable si consideramos que las variaciones en las precipitaciones y el stock son asimétricas y únicamente actúan a nivel de comarca. Para un estudio a nivel de cuenca la presente metodología debería complementarse con un modelo de precios.

${ }^{26}$ Las subvenciones, en caso de que las haya, se consideran una cantidad fija independiente de la producción, en línea con el proceso de desvinculación que se sigue en la nueva PAC.
} 
jornales de MOv promedio empleados en ese cultivo $\left(J_{t}^{v}\right)$ por el coste del jornal $(\zeta)$ y una variable que relaciona la necesidad de contratar trabajadores eventuales para un nivel de producción dado (resultado del cociente entre producción observada menos producción mínima en los escenarios analizados y producción máxima menos producción mínima dentro los escenarios analizados). Los parámetros referentes al número de jornales y el coste del jornal se extraen del Informe Técnico Económico de Sistemas de Explotación Agrarias (MARM, 2007):

$$
\begin{gathered}
M O f_{t}=J_{t} * \zeta \\
M O f_{t}=Q_{t} * \eta *\left(\frac{Q_{t}-Q_{t \min }}{Q_{\text {tmáx }}-Q_{\text {tmin }}}\right)
\end{gathered}
$$

Los CA se calculan multiplicando el precio del agua en euros por metro cúbico (MARM, 2007) por la cantidad de agua demandada para el nivel de producción alcanzado, lo que depende de la pluviometría del escenario considerado y de las decisiones de dotación de agua para regadío adoptadas por las instituciones competentes en el inicio de la campaña de riego, que como se vio dependen del nivel de stock en los embalses:

$$
C A_{t}=\text { Min }(\text { NNHHe, Dotaciones })_{t} * \theta
$$

La metodología desarrollada en este apartado permite calcular la producción, el valor de esta producción y el Margen Neto de Explotación. A continuación se obtienen estos valores para el limonero y el olivar de aceituna de aceite en las comarcas de Campo de Cartagena y La Campiña para los distintos escenarios de precipitaciones y stock embalsado considerados.

\section{RESULTADOS}

A partir de las funciones de producción desarrolladas en el apartado 2.1 y conocido el porcentaje de evapotranspiración satisfecha en cada escenario de precipitaciones y stock almacenado se calculan las producciones del olivar de aceituna de aceite y el limonero en ambas comarcas (Anexo II). Partiendo de estas producciones y la cantidad de agua necesarias para obtenerlas, se aplican los coeficientes de precios, subvenciones y costes (MARM, 2007) para calcular el Margen Neto de Explotación correspondiente a cada escenario.

Las siguientes figuras recogen el Margen Neto de Explotación del olivar de aceituna de aceite y del limonero en $€ /$ ha en función del nivel de precipitaciones para distintos escenarios de stock embalsado en las cuencas del Guadalquivir y del Segura: 


\section{Figura 3}

Margen Neto de Explotación (MNE) en €/ha para el limonero en la comarca de Campo de Cartagena para distintos escenarios de llenado del embalse, Cuenca del Segura

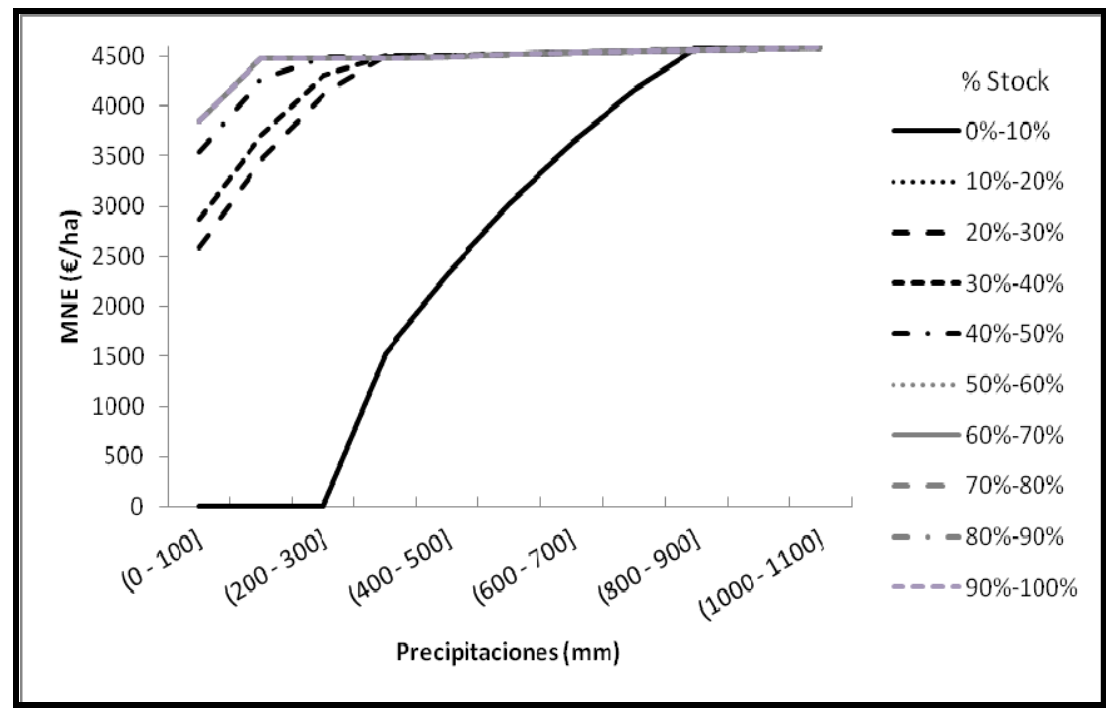

Fuente: Elaboración propia.

\section{Figura 4}

Margen Neto de Explotación (MNE) en €/ha para el limonero en la comarca de La Campiña para distintos escenarios de llenado del embalse, Cuenca del Guadalquivir

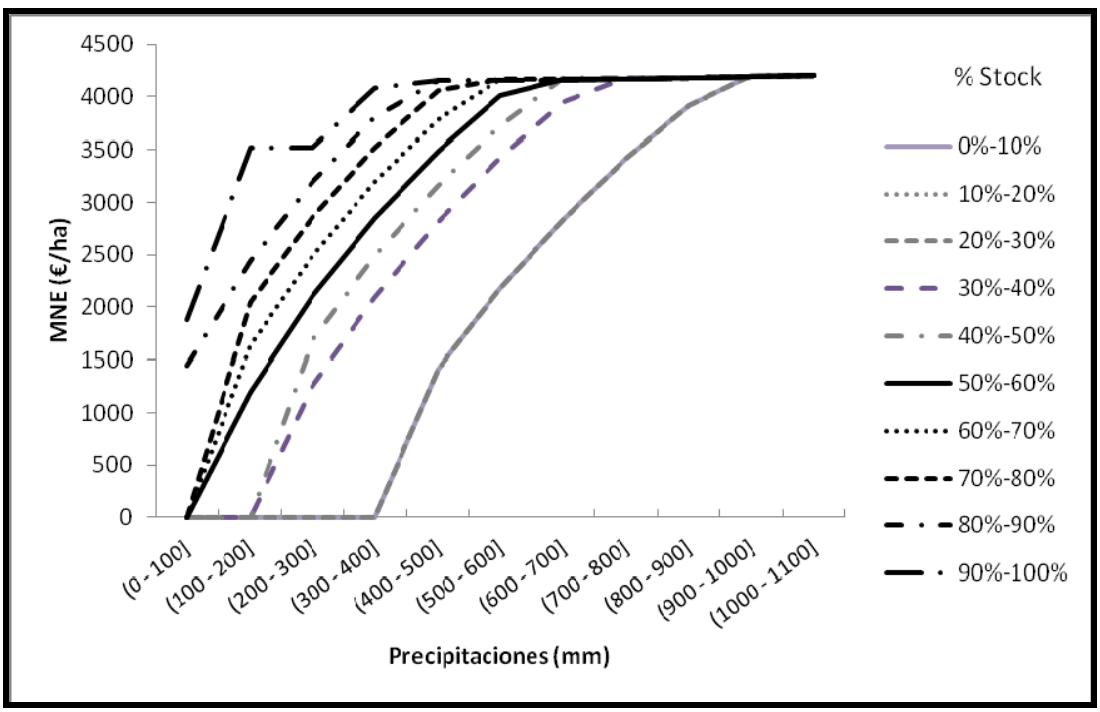

Fuente: Elaboración propia. 
Los resultados muestran que las rentas generadas por el limonero en años hidrológicos normales (sin sequía) son superiores en la comarca de Campo de Cartagena (4600 €/ha) que en la de La Campiña (4100 €/ha). Esta diferencia se produce a pesar de que los niveles de producción esperados en kilogramos por hectárea son similares en ambas comarcas. El motivo principal para explicar la brecha existente en los márgenes se debe a la diferencia en los costes de producción por kilogramo de producto, notablemente inferiores en Campo de Cartagena debido a la existencia de economías de escala en la producción de cítricos.

Además, el limonero en Campo de Cartagena genera rentas sistemáticamente superiores en todos los escenarios de escasez considerados, si bien estos resultados han de ser reinterpretados atendiendo a las probabilidades de estos escenarios en cada una de estas comarcas (Anexo I).

En efecto, a pesar de los mayores márgenes, Campo de Cartagena es una zona árida y propensa a sufrir periódicamente sequías duraderas y de intensidad variable (CHS, 2007). Esto hace que las probabilidades de sequía sean mayores en esta comarca (Anexo I). Así, la probabilidad de obtener márgenes inferiores al 50\% del Margen Neto de Explotación máximo o que se obtendría en un año hidrológico normal (sin sequía) es del $11,07 \%$ en esta comarca, por tan solo el $2,3 \%$ de La Campiña, lo que hace a los productores mucho más vulnerables a la sequía en la comarca del Segura. A pesar de ello, el Margen Neto de Explotación esperado ${ }^{27}$ para el limonero en Campo de Cartagena sigue siendo superior $(3989,86 € / \mathrm{ha})$ al de La Campiña $(3771,73 € / \mathrm{ha})$, si bien en este punto cabe considerar el desarrollo de un análisis más complejo que integrara en la función de decisión del agricultor, además de los citados márgenes, la aversión al riesgo (mayor en Campo de Cartagena).

Frente a la variabilidad en la producción de los cítricos, con márgenes esperados en La Campiña y Campo de Cartagena que apenas alcanzan el 89,8\% y el $87 \%$ del Margen Neto de Explotación en un año hidrológico normal, respectivamente, el olivar, en su condición de cultivo tradicionalmente de secano, soportado por riegos de apoyo, ofrece unas rentas significativamente más estables (el Margen Neto de Explotación esperado es del 99\% del de un año hidrológico normal en La Campiña, y del $89,1 \%$ en Campo de Cartagena), si bien también muy inferiores (el Margen Neto de Explotación máximo es de 737 $€ /$ ha en La Campiña y 291,5 €/ha en Campo de Cartagena).

27 El MNE esperado es el resultado de sumar el producto del MNE correspondiente a cada estado de naturaleza por la probabilidad asociada a este estado. 


\section{Figura 5}

Margen Neto de Explotación (MNE) en €/ha para el olivar de aceituna de aceite en la comarca de La Campiña para distintos escenarios de llenado del embalse, Cuenca del Guadalquivir

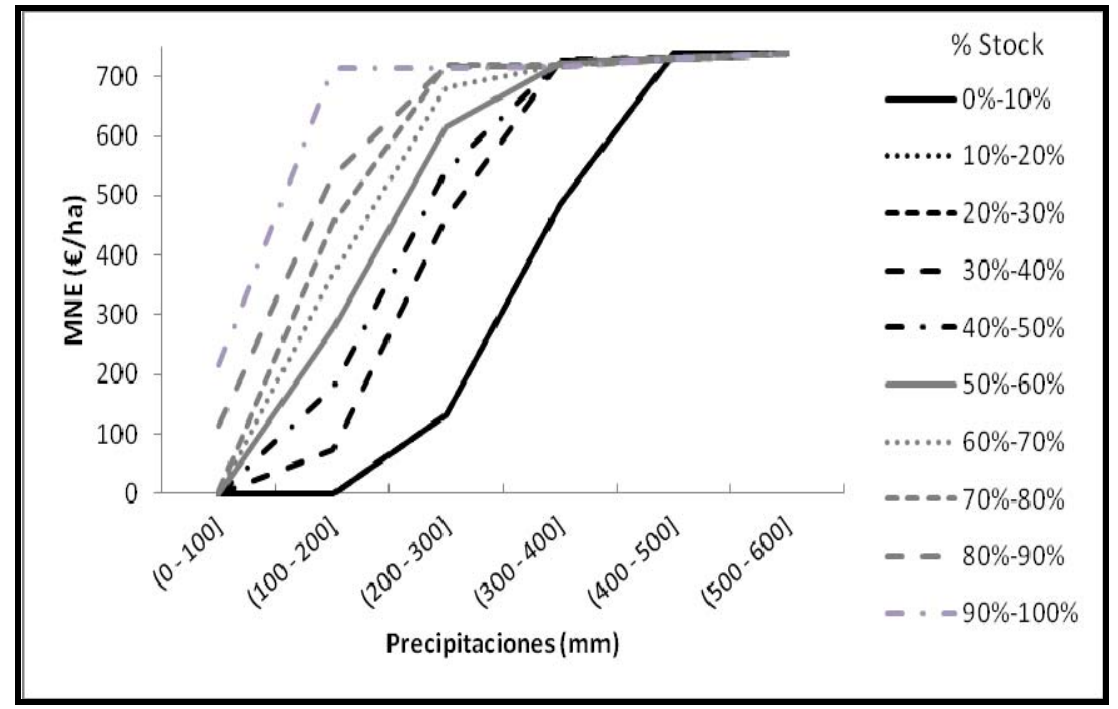

Fuente: Elaboración propia.

\section{Figura 6}

Margen Neto de Explotación (MNE) en €/ha para el olivar de aceituna de aceite en la comarca de Campo de Cartagena para distintos escenarios de llenado del embalse, Cuenca del Segura

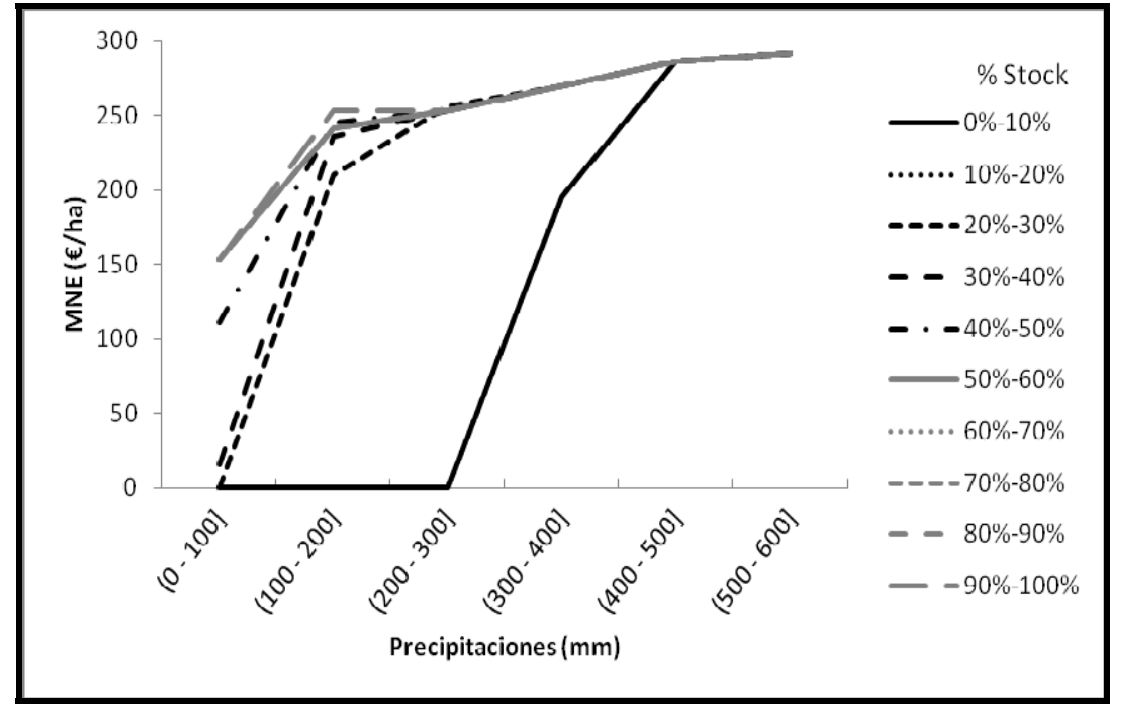

Fuente: Elaboración propia. 


\section{CONCLUSIONES}

La comarca de Campo de Cartagena tiene una de las agriculturas más rentables de Murcia y de España gracias al desarrollo de un pujante regadío en la región (CHS, 2008). No obstante, la aridez de la cuenca y la mayor exposición a la sequía que previsiblemente se derivará de la aprobación y eventual aplicación del Plan de Sequía de la Cuenca del Segura hacen que el riesgo que debe afrontar la agricultura intensiva en regadío sea muy elevado. $\mathrm{Si}$ bien el Margen Neto de Explotación esperado de cultivos como el limonero sigue siendo mayor en Campo de Cartagena que en otras regiones también rentables como La Campiña, existe una mayor exposición al riesgo que puede derivar en significativas pérdidas económicas.

Los resultados obtenidos indican que la aplicación de las normas de decisión de los Planes de Sequía suponen un aumento significativo del riesgo económico y financiero al que se encuentra expuesto el regadío de la Cuenca del Segura. La gestión de la sequía, en ese sentido, no resuelve y es probable que contribuya al agravamiento de los problemas de sostenibilidad de la agricultura mediterránea española. Las simulaciones realizadas demuestran por ejemplo que, de producirse en Campo de Cartagena otra sequía como la del período 2005-2008 (en que los embalses estuvieron por debajo del umbral de emergencia del $20 \%$ previsto por el Plan de Sequía), las pérdidas anuales podrían llegar al $100 \%$ del margen con un $21 \%$ de probabilidad (es decir, en una cada cinco campañas agrarias), con una pérdida esperada de más de $3000 € /$ ha y año $(65,2 \%$ del margen). Es probable que, al disminuir la garantía de suministro, las nuevas reglas de sequía incentiven el uso no controlado de agua subterránea y promuevan comportamientos de riesgo moral que, en contra de lo previsto, disminuyan la capacidad de respuesta al riesgo de sequía en el futuro.

El trabajo presentado en este artículo permite avanzar en la búsqueda de alternativas productivas con mayor resiliencia y menor exposición al riesgo de sequía. De acuerdo, por ejemplo, con los resultados obtenidos, los cultivos menos vulnerables a la sequía, como el olivar, constituyen una alternativa aceptable en La Campiña, donde la vulnerabilidad de esta planta a la sequía es mínima (el Margen Neto de Explotación esperado es el 99\% del MNE máximo) y las rentas son comparativamente aceptables (la renta esperada del olivar en esta comarca es el $19,4 \%$ de la del limonero). Por el contrario, en Campo de Cartagena, recuperar el olivar implicaría renunciar al 93,5\% del margen esperado, y la aridez de la cuenca haría que la vulnerabilidad ante la sequía apenas disminuyera (el Margen Neto de Explotación esperado sobre el máximo pasaría del $87 \%$ al $89,1 \%$ ).

Los resultados anteriores permiten concluir que aunque los Planes de Sequía constituyen una herramienta garantista de los usos prioritarios de abastecimiento urbano, estos no solo no resuelven sino que comprometen aún 
más la sostenibilidad del regadío español de alto rendimiento ubicado en zonas áridas del suroeste español. Si no se desarrollan las herramientas de política económica adecuadas, la sequía puede derivar en pérdidas económicas aun mayores para regiones altamente expuestas y con estructura deficitaria como las de la Cuenca del Segura, contribuyendo a exacerbar el conflicto del agua. Aunque menos graves, las pérdidas esperadas también son significativas en el caso de La Campiña, especialmente si se comparan con alternativas como el olivar.

Pueden mencionarse varias alternativas complementarias para reducir la exposición al riesgo de la agricultura de regadío. El mayor riesgo supone una debilidad importante para el desarrollo rural y si no se encontraran instrumentos alternativos o complementarios de los actuales Planes de Sequía, los excesos de capacidad productiva a corto plazo podrían convertirse en abandono de explotaciones y en una paralización de las inversiones de reposición de la capacidad productiva. Debido al papel dinamizador del desarrollo rural del regadío, todo esto supone una amenaza para un conjunto de actividades asociadas a la agricultura. Por ejemplo, un seguro agrario es una alternativa conservadora pero funcional, que contribuye a reducir la sensación de riesgo percibida por los agricultores y a estabilizar las decisiones de acumulación de capital; si bien es una medida paliativa que no soluciona el problema de escasez estructural de agua, sí permite reducir la variabilidad y el riesgo asociado a la pérdida de ingreso y puestos de trabajo y sus consecuencias sobre los eslabonamientos hacia atrás (demanda de maquinaria agrícola, abonos, fitosanitarios, etc.) y hacia delante (industria alimentaria, sector exportador, etc.) (Pérez et al., 2010).

En este sentido hay propuestas interesantes en el camino de desarrollar mercados de agua (Tirado et al., 2006) o políticas de precios (Gómez, 2009) para garantizar que los recursos hídricos fluyan hacia los sectores y regiones más productivos. Del éxito en la aplicación de estos Instrumentos de Política Económica depende en buena medida la continuidad del regadío en zonas como el Campo de Cartagena y, en menor medida, La Campiña

\section{REFERENCIAS BIBLIOGRÁFICAS}

ALLEN, E.; PEREIRA, L. S.; RAES, D.; y SMITH, M. (2006). Evapotranspiración del cultivo. Guías para la determinación de los requerimientos de agua de los cultivos. Roma: Organización de las Naciones Unidas para la Agricultura y la Alimentación (FAO). 
CONFEDERACIÓN HIDROGRÁFICA DEL GUADALQUIVIR (CHG) (2008). Esquema Provisional de Temas Importantes (EPTI). http://www.chguadalquivir.es/export/sites/default/portalchg/planHidrologicoD emarcacion/participacionPublica/informacion/ficheros/Folleto_ETI_definitivo. pdf [Último acceso: febrero de 2011].

CONFEDERACIÓN HIDROGRÁFICA DEL GUADALQUIVIR (CHG) (2010). Plan Especial de Actuación en Situaciones de Alerta y Eventual Sequía. http://www.mma.es/secciones/acm/aguas_continent_zonas_asoc/ons/plane s_sequia_isas/pdf/GUADALQUIVIR_cap01.pdf [Último acceso: febrero de 2011].

CONFEDERACIÓN HIDROGRÁFICA DEL SEGURA (CHS) (2010). Plan Especial de Actuación en Situaciones de Alerta y Eventual Sequía. http://www.chsegura.es/chs/cuenca/sequias/pes/eeapes.html\#doc_completa [Último acceso: febrero de 2011].

CONFEDERACIÓN HIDROGRÁFICA DEL SEGURA (CHS) (2008). Esquema Provisional de Temas Importantes (EPTI). http://www.chsegura.es/export/descargas/planificacionydma/planificacion/do csdescarga/ETI_v6_29julio2008.pdf [Último acceso: febrero de 2011].

CONFEDERACIÓN HIDROGRÁFICA DEL SEGURA (CHS) (2006). Estudio de Actualización de las demandas a atender por la Mancomunidad de los Canales del Taibilla en el horizonte del Plan Hidrológico. Murcia: Confederación Hidrográfica del Segura. .

CONFEDERACIÓN HIDROGRÁFICA DEL SEGURA (CHS) (2006). La gestión del Servicio 2006. Murcia: Confederación Hidrográfica del Segura.

DINAR, A; y SALETH, M. (2005). "Can Water Institutions be Cured? A Water Institutions Health Index". Water Science and Technology: Water Supply, 15(6), pp. 17-40.

EUROPEAN ENVIRONMENT AGENCY (EEA) (2009). Water resources across Europe - confronting water scarcity and drought. Bruselas: EEA Report $\mathrm{n}^{\circ}$ 2/2009.

GÓMEZ-RAMOS, A.; IGLESIAS, E.; y GARRIDO, A. (2002). "Evaluación de la garantía de suministro de agua en la agricultura: Una aplicación a la Cuenca del Guadalquivir". Ingeniería del Agua, 3(9), pp. 279-294.

GÓMEZ, C. M. (2009). "La eficiencia en la asignación del agua: principios básicos y hechos estilizados en España". Información Comercial Española, Economía y Medio Ambiente, 847(23), pp. 23-39.

INSTITUTO ANDALUZ DE REGADÍOS (IAR) (2010). Plan Andaluz de Regadíos. Sevilla: Consejería de Medio Ambiente.

MAESTU, J.; GÓMEZ, C. M.; y GUTIÉRREZ, C. (2007). El agua en la economía española: situación y perspectivas. Informe Integrado del Análisis Económico de los Usos del Agua. Madrid: Ministerio de Medio Ambiente y Medio Rural y Marino. 
MARTIN, S.; BARNETT, B.; y COBLE, K. (2001). "Developing and pricing precipitation insurance". Journal of Agricultural and Resource Economics, 26(1), pp. 261-274.

McWORTHER, J. C.; MATTHES, R. K.; y BROOKS Jr., B. P. (1966). Precipitation Probabilities for Mississippi. Mississippi State University: Water Resources Research Institute.

MINISTERIO DE MEDIO AMBIENTE (MMA) (2005). Guía para la redacción de Planes Especiales de Actuación en situación de Alerta y Eventual Sequía. Madrid.

MINISTERIO DE MEDIO AMBIENTE Y MEDIO RURAL Y MARINO (MARM) (2007). Informes Técnicos de Sistemas de Explotación Agraria. Madrid.

MINISTERIO DE MEDIO AMBIENTE Y MEDIO RURAL Y MARINO (MARM) (2009). Encuesta sobres Superficies y Rendimientos de Cultivos en España (ESYRCE). http://www.mapa.es/es/estadistica/pags/encuestacultivos/resultados.htm [Último acceso: febrero de 2011].

MINISTERIO DE MEDIO AMBIENTE Y MEDIO RURAL Y MARINO (MARM) (2009). Anuario de Aforos 2007-2008. http://hercules.cedex.es/anuarioaforos/default.asp. [Último acceso: febrero de 2011].

PASTOR, M.; HIDALGO, J.; ORGAZ, F.; MORIANA, A.; y FERERES, E. (2002). Riego del olivar: estudio de la respuesta a riegos por goteo deficitarios y obtención de la función de producción. Actas de las I Jornadas Técnicas del Aceite de Oliva. Madrid: Ed. Ministerio de Ciencia y Tecnología.

PÉREZ, C. D.; GÓMEZ, C. M.; y GARRIDO, R. (2010). "Cambio estructural regional y agua: escasez, dependencia e impactos sobre el tejido económico. El caso de Andalucía". Estudios de Economía Aplicada, 28(2), pp. 423-446.

SEVILLA JIMÉNEZ, M.; TORREGROSA, T.; y MORENO, L. (2010). "Las aguas subterráneas y la "tragedia de los comunes en el Vinalopó" (Alicante, España)". Estudios de Economía Aplicada, 28(2), pp. 305-332.

SINDICATO CENTRAL DE REGANTES DEL ACUEDUCTO TAJO-SEGURA (SCRATS) (2005). Informe sobre las repercusiones de la sequía 2004-2005. Murcia: Sindicato Central de Regantes del Acueducto Tajo-Segura.

SALETH, M.; y DINAR, A. (1999). "Water Challenge and Institutional Response: A Cross Country Perspective". The World Bank Development Research Group. Rural Development Department. Policy Research, Working Paper 2045.

TIRADO, D.; GÓMEZ, C. M.; y LODAZON, J. (2006). "Efficiency improvements and water policy in the Balearic Islands: A General Equilibrium Approach". Investigaciones Económicas, XXX, pp. 441-463.

YOUNG R. (2005). Determining the Economic Value of Water: Concepts and Methods. Washington: Resources for the Future. 


\section{Anexo I}

Tabla 4

Matriz de probabilidades de escenarios, Cuenca del Segura

\begin{tabular}{|c|c|c|c|c|c|c|c|c|c|c|}
\hline $\begin{array}{l}\text { 覃 } \\
\text { 产 }\end{array}$ & 愛 & 产 & 言 & 鰩 & 言 & 产 & 害 & 番 & 悉 & 畹 \\
\hline 훌 & 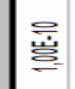 & 总 & 总 & 噃 & 憲 & 曽 & 总 & 总 & 㦚 & 芯 \\
\hline 룽 & 总 & 总 & 害 & 急 & 喼 & 总 & 罖 & 悲 & 畺 & 总 \\
\hline 흘 & 善 & 囩 & 总 & 䊕 & 产 & 总 & 总 & 总 & 吢 & 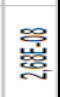 \\
\hline & 产 & 总 & 兽 & 惫 & 畹 & 总 & 总 & 氪 & 惡 & 㐯 \\
\hline $\begin{array}{l}\text { 拳 } \\
\text { 产 }\end{array}$ & 鳏 & 总 & 总 & 息 & 恚 & 悲 & 視 & 㩊 & 鲶 & 兽 \\
\hline 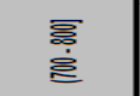 & 㖓 & 喜 & 总 & 㦂 & 帮 & 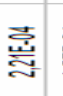 & $\begin{array}{l}\text { 壱 } \\
\text { 恶 }\end{array}$ & 总 & 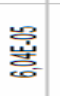 & 䆧 \\
\hline 章 & 憲 & 怘 & 隠 & 誉 & 总 & 惌 & 縂 & 壱 & 謍 & 䓌 \\
\hline $\begin{array}{l}\text { 军 } \\
\text { 亶 }\end{array}$ & 㖓 & 番 & 荧 & 总 & 恚 & 営 & 总 & 愛 & 恕 & 恚 \\
\hline & 㥕 & 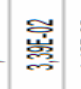 & 憲 & 鸪 & 善 & 惫 & 䓌 & 胥 & 总 & 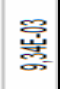 \\
\hline 章 & 亲 & 愛 & 害 & 怘 & 番 & 急 & 善 & 㤩 & 氶 & 㥯 \\
\hline 룩 & 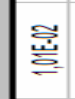 & 害 & 害 & 㥯 & 总 & 㺃 & 急 & 总 & 悲 & 㟔 \\
\hline 章 & 预 & 蛊 & 嵒 & 誉 & 夢 & 总 & 总 & 营 & 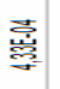 & 㩊 \\
\hline & 产 & 罜 & 总 & 鰨 & 总 & 曽 & 裹 & 矛 & 意 & 憲 \\
\hline 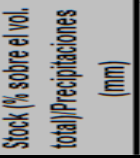 & $\underline{\bar{g}}$ & $\stackrel{\bar{\Xi}}{\bar{\Xi}}$ & 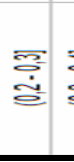 & 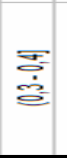 & 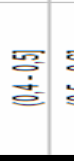 & $\begin{array}{l}\text { 흘 } \\
\dot{g}=\end{array}$ & $\begin{array}{l}\underset{\vec{g}}{\dot{g}} \\
\dot{\theta}=\end{array}$ & 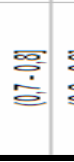 & 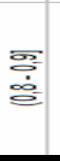 & $\overline{\vec{s}}$ \\
\hline
\end{tabular}

Fuente: Elaboración propia. 
Tabla 5

Matriz de probabilidades de escenarios, Cuenca del Guadalquivir

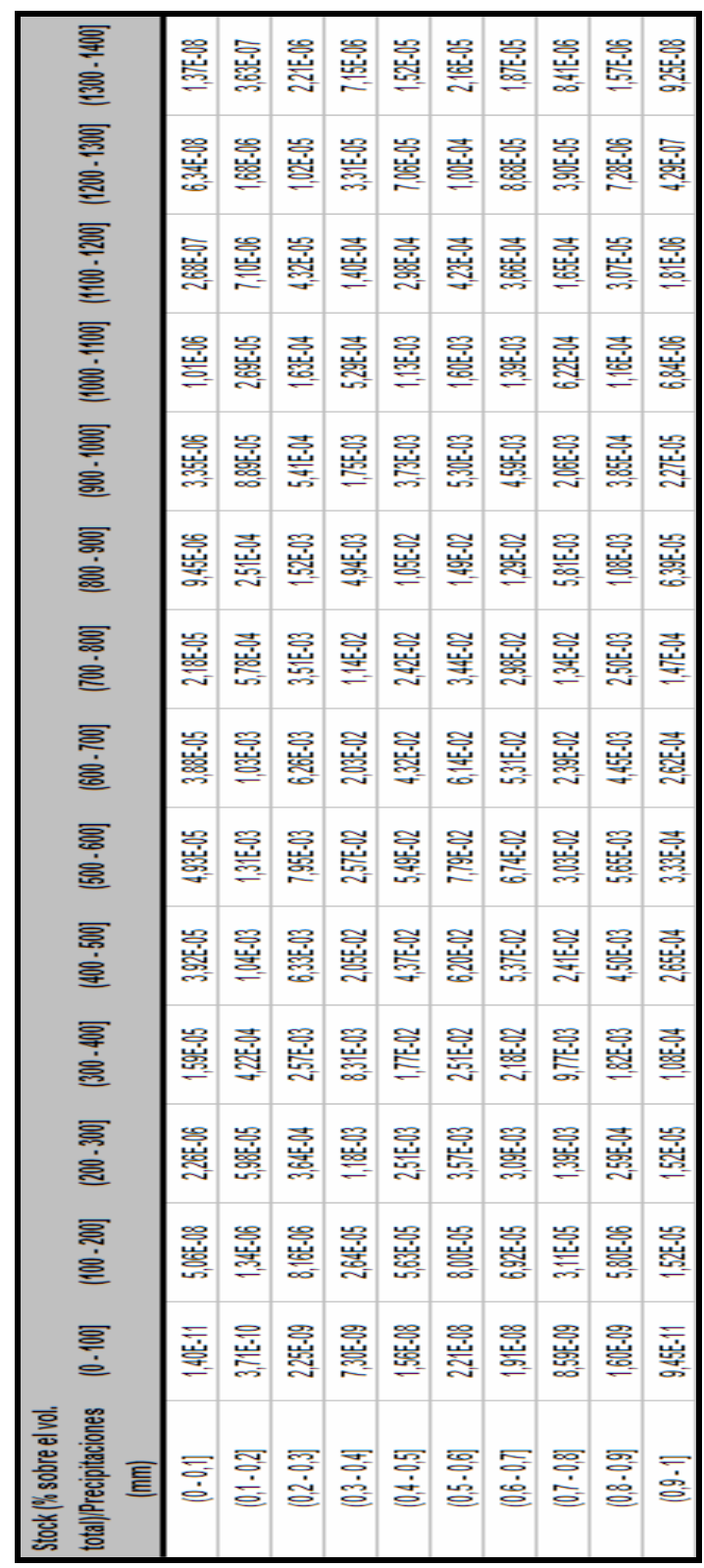

Fuente: Elaboración propia. 


\section{Anexo II}

Figura 7

Rendimientos en $\mathrm{kg} / \mathrm{ha}$ para el olivar de aceituna de aceite en la comarca de La Campiña para distintos escenarios de llenado del embalse, Cuenca del Guadalquivir

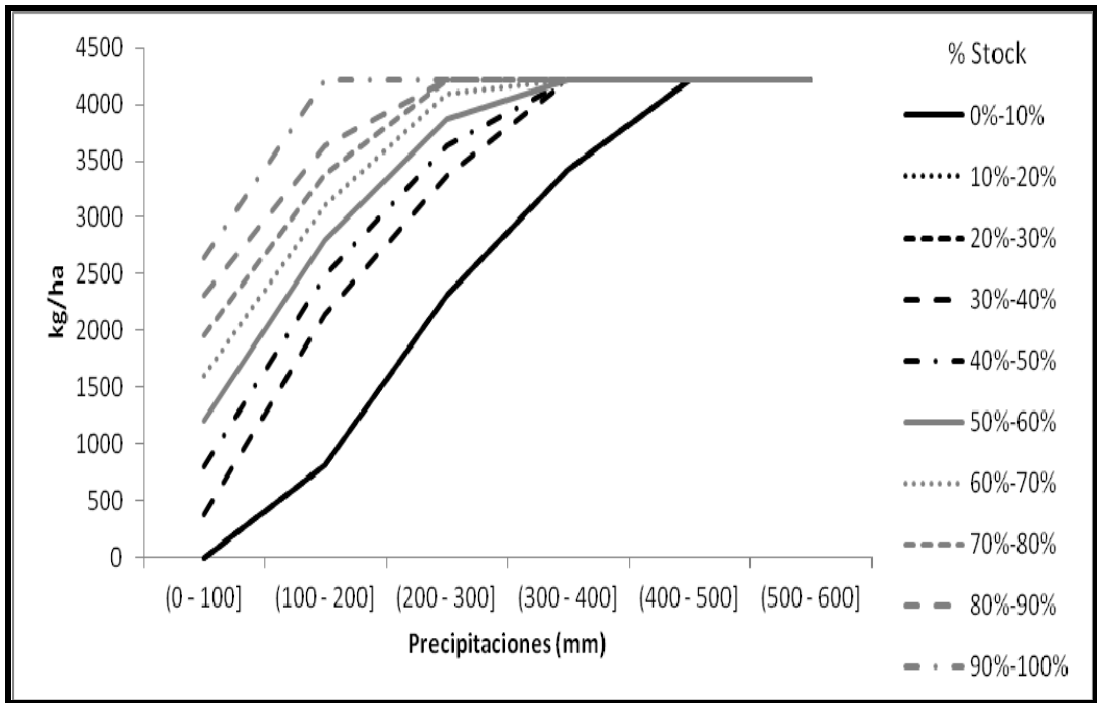

Fuente: Elaboración propia.

Figura 8

Rendimientos en $\mathrm{kg} / \mathrm{ha}$ para el olivar de aceituna de aceite en la comarca de Campo de Cartagena para distintos escenarios de llenado del embalse, Cuenca del Segura

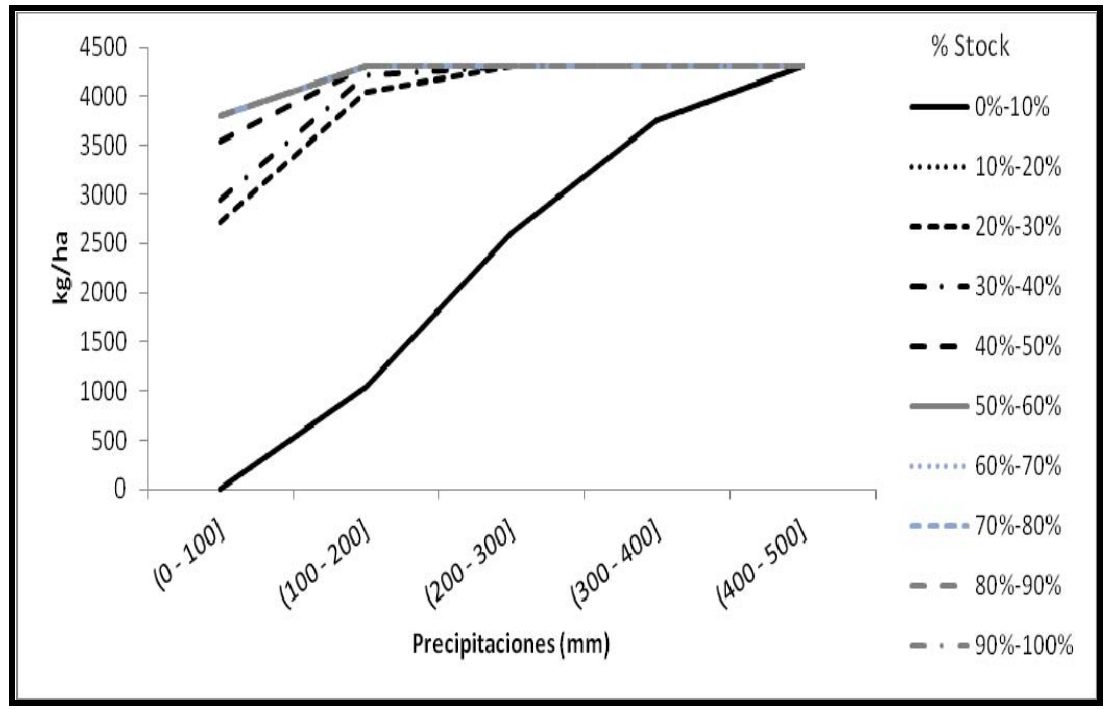

Fuente: Elaboración propia. 


\section{Figura 9}

Rendimientos en kg/ha para el limonero en la comarca de La Campiña para distintos escenarios de llenado del embalse, Cuenca del Guadalquivir

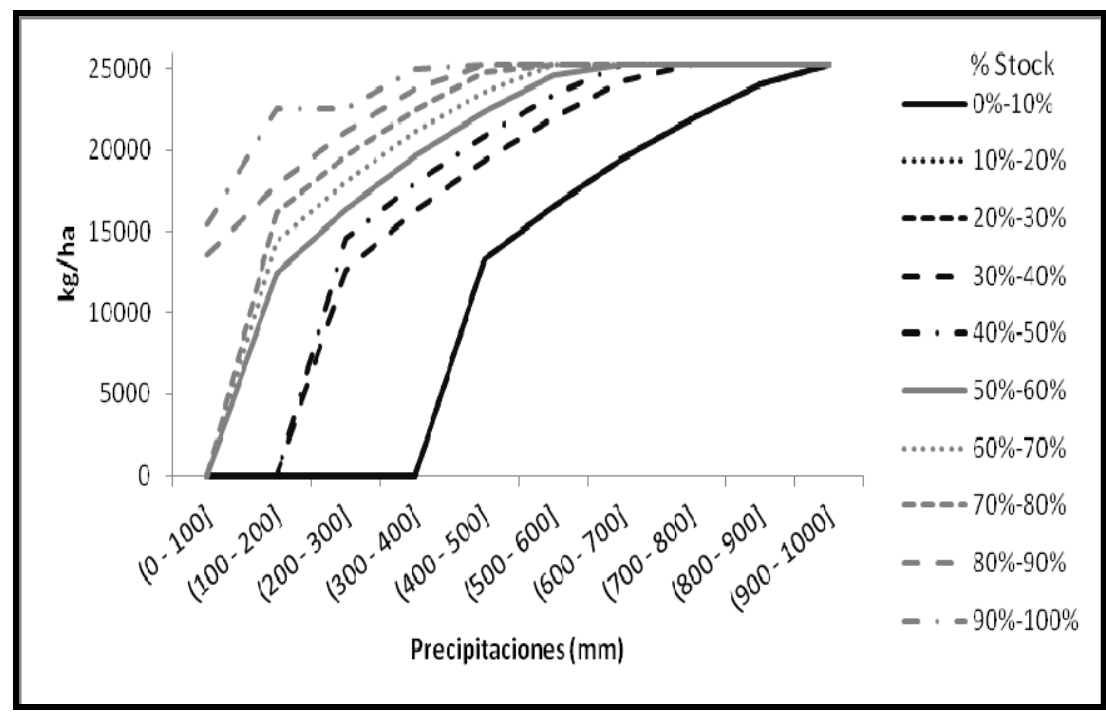

Fuente: Elaboración propia.

Figura 10

Rendimientos en $\mathrm{kg} / \mathrm{ha}$ para el limonero en la comarca de Campo de Cartagena para distintos escenarios de llenado del embalse, Cuenca del Segura

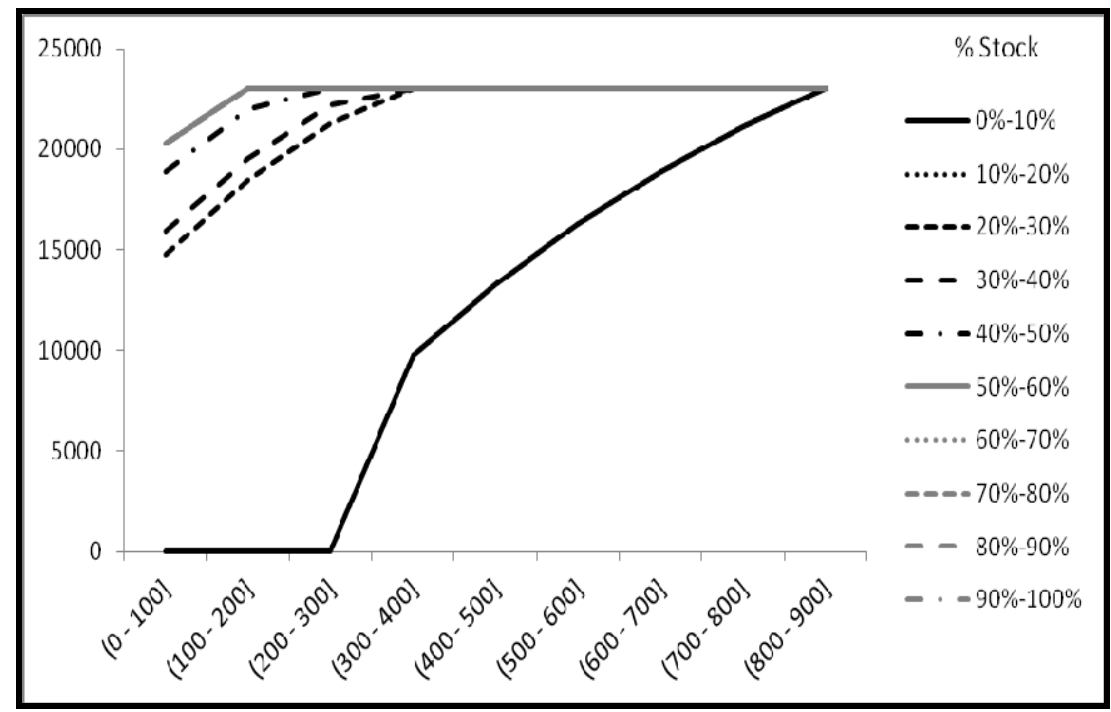

Fuente: Elaboración propia. 
